Алексей Дмитриевич Шмелев

Россия, Институт русского языка РАН

\title{
Вопросы пунктуации в работе Орфографической комиссии Российской академии наук: лингвистические основы кодификации ${ }^{1}$
}

Ключевые слова: кодификация языковых норм, пунктуация, знак препинания, узус, вариативность.

Key words: codification of linguistic standards, punctuation, punctuation mark, usage, variation.

\section{Abstract}

This paper claims that a clear realization of the general principles of codification of punctuation should precede the work on creating a complete set of rules for Russian punctuation. Disputes among linguists on the qualification of new phenomena in punctuation are clear evidence of the absence of generally accepted criteria for assessing codification of norms. The proposed integrated approach to the codification of punctuation norms combines the results of observation over usage (taking into account the social variation of usage) with results of interviews.

It is necessary to distinguish between analytical and synthetic approaches. Within the analytical approach, a given punctuation mark serves the starting point for further investigation: the researchers seek to provide most accurate account of its functions. Within the synthetic approach, a given syntactic position is the starting point: one should establish whether it requires a punctuation mark and, if so, which one. Rules of punctuation require the synthetic approach while theoretical grounds for them may be better discovered within the analytical approach.

The codification consists of two stages, namely, (i) deciding whether a punctuation mark is appropriate in a given syntactic position, and (ii) stating the corresponding rule. Often the codifiers do not distinguish between those two stages.

1 Исследование выполнено при финансовой поддержке РФФИ в рамках научного проекта № 1801200778. 
The Commission for Orthography of the Russian Academy of Sciences analyzes discrepancies between rules for punctuation and usage. In addition, the Commission studies variation of punctuation standards as well as some specific issues of punctuation. These issues will be reflected in a new punctuation code.

В статье рассматриваются вопросы пунктуации, обсуждавшиеся на заседаниях Российской академии наук - в первую очередь, в сообщениях автора данной статьи. Трудность в поисках научных основ кодификации пунктуации во многом обусловлена тем, что применительно к пунктуации (в отличие от орфографии) важно разграничивать аналитическую и синтетическую стратегию: при аналитической стратегии исследователь идет от конкретного знака препинания и пытается максимально точно описать его функции, а при синтетической от конкретной позиции в предложении, в которой необходимо определить, нужен ли знак препинания и, если да, то какой. Научное изучение русской пунктуации в основном ведется посредством аналитической стратегии, т.е. в режиме «от знака к смыслу», тогда как формулировка правил пунктуации должна строиться посредством синтетической стратегии, т.е. в режиме «от позиции в тексте к знаку».

При этом правила пунктуации часто строятся по принципу «синтез через анализ»: выявляется синтаксическое строение фразы и ее смысл, устанавливаются особенности ее интонирования при чтении вслух. Пунктуация выбирается таким образом, чтобы значения указанных параметров соответствовали замыслу или пониманию пишущего.

Существенно, что общий подход к кодификации правописания, разработанный автором данной статьи, предполагает, что нет непроходимой границы между нормами правописания и прочими языковыми нормами. Среди лингвистов в течение долгого времени было распространено мнение, согласно которому нормы правописания имеют совсем другой статус, нежели прочие языковые нормы: они являются чем-то внешним по отношению к языку и, в отличие от прочих языковых норм, складывающихся в некотором смысле стихийно, вводятся решением компетентных инстанций и потому являются относительно «произвольными». Это связано с тем, что нормы правописания гораздо легче вводить и поддерживать (т.е. следить за их соблюдением), используя различного рода репрессивные механизмы. Однако многочисленные факты, касающиеся истории как русского правописания, так и правописания ряда других языков, свидетельствуют, что граница никак не является абсолютной. При кодификации правописания важную роль приобретает понятие «грамотного письма», т.е. способов написания, которое образованные носители языка готовы счесть «правильным».

Необходимость кодификации норм возникает при наличии реальной или хотя бы потенциальной вариативности в узусе. В этом случае необходима экспертная оценка. Необходимо установить, какой из вариантов следует 
объявить «правильным» (возможна также вариативность нормы: правильно «и так, и так»). В триаде узус - норма - кодификация непосредственному наблюдению подвержены первый и последний члены триады: реальная речевая практика носителей языка и описание языковой нормы в нормативных справочниках. При этом кодификация в целом более консервативна, нежели узус. Что касается нормы, она реконструируется на основе наблюдения над узусом и соотнесения данных наблюдений как с данными справочников, так и с эксплицитными суждениями носителей нормы (образованных носителей языка). Пунктуационную норму невозможно непосредственно вывести из узуса, пусть даже «практики печати», но, с другой стороны, ее нельзя задать произвольно, «волевым решением», пусть даже это решение кажется кодификаторам вполне логичным. При установлении нормы предлагается ориентироваться не столько на узус, сколько на сознательную оценку, которую носители нормы дают степени нормативности вариантов, существующих в узусе. При этом множество носителей нормы устанавливается отдельно для каждой отдельной рекомендации (в любом случае в их число попадают специалисты, занимающиеся нормализацией). Иными словами, само понятие о норме возникает, когда в узусе наблюдается (или хотя бы может наблюдаться) вариативность, так что у носителей языка возникает желание как-то оценить эти варианты. При этом существенно, что какие-то варианты оцениваются носителями языка как «неправильные» или хотя бы менее желательные. Для выработки нормативных рекомендаций существенно не то, какой вариант выбирает «некомпетентный» носитель языка, не знакомый с существующими рекомендациями, а то, как «компетентный» носитель языка (носитель нормы), опирающийся на рекомендации справочников и словарей, оценивает существующие варианты.

В качестве основных методов исследования, на которые опирались члены Орфографической комиссии, занимающиеся вопросами пунктуации, использовались наблюдение и эксперимент. Объектом наблюдения служили пополняющиеся электронные корпусы русских текстов (в первую очередь «Национальный корпус русского языка» и корпус сайта «Журнальный зал»), а также тексты ежегодного «Тотального диктанта» и возникающие время от времени в ходе проверки диктанта дискуссии между проверяющими. Для получения экспериментальных данных был проведен ряд опросов образованных носителей русского языка, в частности членов Орфографической комиссии; при этом учитывалась социолингвистическая характеристика полученных результатов. Опросы членов Орфографической комиссии РАН по спорным моментам и наблюдение над спорами между проверяющими «Тотального диктанта» позволили выявить ряд трудных и нерешенных моментов русской пунктуации.

Кратко охарактеризую принятый подход. 
Членов языкового сообщества, авторитетных по некоторому вопросу, связанному с языковой нормой (в нашем случае - по вопросам пунктуации), можно условно назвать «экспертами» (по данному вопросу). Важнее всего не то, что «эксперты» считают «правильным», а те явления в узусе, которые они воспринимают как «неправильные», что обращает на себя их внимание как «неправильность». Задача описательной кодификации заключается в том, чтобы выявить мнение экспертов и зафиксировать его в правилах и справочниках (или каким-то иным доступным кодификатору способом). Здесь могут быть (и бывают) разные ситуации: например, когда все эксперты в общем согласны между собою и когда их мнения полностью противоречат одно другому (в последнем случае желательно попытаться установить, чем обусловлено противоречие). «Наивные» кодификаторы, не проведшие соответствующего исследования, могут в лучшем случае котироваться как «эксперты», и их мнение может учитываться описательной кодификацией, но именно как мнение «экспертов».

Из всего сказанного никак не следует, что узус безразличен для описательной кодификации. Некоторые «эксперты» могут в своих оценках опираться именно на него. Но роль узуса опосредованная, связанная с его влиянием на оценки «экспертов» (другие «эксперты» могут ориентироваться на что-то еще).

Необходимо разграничивать нормы правописания и правила правописания (это разграничение было, в частности, проведено в статье [Šmelev 2009]). Норма правописания позволяет охарактеризовать то или иное написание как «грамотное» или «неграмотное», тогда как правило правописания формулирует критерии, позволяющие осуществить такое отнесение. Для одной и той же нормы иногда можно сформулировать разные правила, и в таких случаях выбор формулировки зависит от того, насколько она ясна и логична.

Тем самым кодификация состоит из двух этапов, которые до сих пор иногда смешивались кодификаторами: на первом этапе должна быть дана оценка нормативности того, что встречается в узусе, а на втором - формулируется само правило. Часто последовательность нарушалась: кодификаторы сначала формулировали правило, а потом оценивали узус с точки зрения того, насколько он соответствует сформулированному правилу. Но Орфографическая комиссия в своей работе неуклонно следует обозначенной последовательности: сначала оценка нормативности явлений узуса, и только затем правило.

Таким образом, можно выделить два типа лакун в существующих правилах правописания: лакуну в правилах (когда норма существует и в целом принимается всеми грамотными носителями языка, однако правила ее не учитывают) и неустановленную норму (когда разные грамотные носители языка предпочитают различное написание одного и того же языкового выражения, а правила либо ничего не говорят на этот счет, либо предписывают написание, противоречащее предпочитаемому многими грамотными носителями языка или даже большинством). 
Все сказанное в полной мере применимо к пунктуационным нормам. Несоответствие пунктуационного узуса и существующих нормативных справочников по пунктуации может интерпретироваться различным образом. Иногда расхождение узуса и нормативных рекомендаций оказывается попросту мнимым: принятые в узусе варианты издавна допускались нормативными словарями и справочниками. Но и в тех случаях, когда расхождение нормативных рекомендаций и грамотного пунктуационного узуса действительно имеет место, это не обязательно свидетельствует о том, что нормы изменились. В ряде случаев описания с самого начала не соответствовали реальному грамотному узусу, так что можно говорить не столько о языковых изменениях, сколько о несовершенстве описаний.

Так, фразу успеет хорошо если за час напишет без запятой после хорошо подавляющее большинство грамотных людей, однако в справочниках, описывающих правила пунктуации, об этом ничего не говорится (на это 26 января 2019 обратил мое внимание Я.Г. Тестелец). Точно так же не ставится запятая и в других случаях, когда подчиняющее предложение как бы вставляется внутрь подчиненного. Ср. примеры из «Национального корпуса русского языка» (далее - НКРЯ):

- Он за всю жизнь хорошо если раза три стрелял из автомата [Г.Я. Бакланов, В месте светлом, в месте злачном, в месте покойном (1995)].

- Куда продуктивнее и интереснее увидеть и запомнить своеобразие их лиц - которое не факт что есть у конкурсных красавиц, но точно есть у лучших оркестров [Я. Тимофеев, Дружба России и Голландии закончилась любовью // Известия, 2013.11.11].

Это лакуна в правилах; норма здесь вполне устоялась, и постановка запятой перед если и что в приведенных примерах была бы не чем иным, как отклонением от нормы. Однако остается вопрос, как отразить эту норму в правилах.

Иной тип лакун составляют некоторые правила пунктуации в деловых и личных письмах. Так, грамотные люди спорят относительно того, следует ли в письме ставить запятую после заключительной формулы перед подписью. Узус здесь вариативен: если заключительная формула исчерпывается словом Ваш или твой, запятая чаще не ставится; если она представляет собою самостоятельное предложение (например, Примите уверения в совершенном почтении или просто Целую), запятую чаще ставят (а иногда даже ставят точку); впрочем, и это не более чем тенденции. А для таких формул, как с глубоким уважением, или с самыми добрыми пожеланиями или искренне $B a w$, единого мнения нет и нет сколько-нибудь стабильного сложившегося узуса. Хотя нередко тот или иной грамотный носитель языка уверенно настаивает на необходимости или, наоборот, недопустимости запятой, но само 
это расхождение во взглядах свидетельствует, что мы имеем дело с неустоявшейся нормой.

Здесь можно добавить, что речевой этикет вообще составляет отдельную проблему при обсуждении кодификации пунктуационных норм. Для речевого этикета характерно нестандартное соотношение нормы и узуса. Дело в том, что правила речевого этикета, вообще говоря, описывают норму, а не узус. С другой стороны, именно в отношении норм речевого этикета как ни в каких других нормах чрезвычайно велики расхождения между представлениями разных носителей нормы относительно того, что «правильно», а что - нет. Пунктуация в деловой переписке, а в последние десятилетия и пунктуационные нормы в электронной переписке составляют предмет нескончаемых споров между носителями языка, озабоченными проблемами грамотности.

Особый тип лакун составляют ситуации, когда имеется довольно четкое правило, но размытыми оказываются критерии его применения к конкретным высказываниям. Так, между согласованными определениями, подчиненными одному слову и не соединенными союзом, ставится запятая, если это однородные определения, и не ставится - если это неоднородные определения. Однако мы не во всех случаях располагаем ясными критериями, позволяющими однозначно определить, являются ли определения однородными. По существу логика здесь включает не только «синтез через анализ», но и «анализ через синтез»: наличие в безупречно грамотном тексте запятой между согласованными определениями, подчиненными одному слову и не соединенными союзом, указывает на то, что пишущий подал определения как однородные. Попытка подыскать для этого внешние обоснования приводит к тому, что формулируются различные, часто логически не соотнесенные условия, при которых определения должны признаваться однородными. По-видимому, следует признать, что есть существенная зона случаев, когда возможна двоякая трактовка и решение остается за пишущим.

Кроме того, внимание уделяется некоторым формальным моментам постановки знаков препинания. Например, в большинстве пособий по пунктуации эксплицитно не отмечается, что знаки конца предложения (точка и вопросительный и восклицательный знаки) не отделяются от последнего слова в предложении пробелом. Это могло бы казать тривиальным, но, скажем, во французских текстах перед вопросительным и восклицательным знаком (но не перед точкой!) требуется пробел.

В рамках работы над сводом правил русской пунктуации было начато систематическое описание соединения и поглощения стоящих рядом знаков препинания: например, в каких случаях один знак может следовать за другим (запятая и скобка могут идти друг за другом только в порядке «скобка - запятая»; точка и восклицательный знак вообще не могут соединиться, а восклицательный знак и многоточие могут, причем в любом порядке). Так, парные знаки (скобки и кавычки) могут заключать в себя как части предложений, 
так и целые предложения (иногда даже несколько). Пунктуация в случае скобок подчиняется следующему правилу: если в скобки заключена часть предложения, то знак конца предложения (точка, вопросительный знак, восклицательный знак, многоточие) ставится после закрывающей скобки, а если в скобки заключено целое предложение, то знак конца предложения ставится перед закрывающей скобкой. В случае кавычек правило несколько иное: если в кавычки заключена часть предложения, то знак конца предложения ставится после закрывающей кавычки, но если в кавычки заключено целое предложение, то вопросительный знак, восклицательный знак или многоточие ставится перед закрывающей кавычкой, но точка - после нее. Эти и другие подобные правила должны быть последовательно отражены в своде правил пунктуации. (Некоторые из таких закономерностей отражены в справочниках корректора и редактора и в «Полном академическом справочнике по орфографии и пунктуации», однако вопросы такого рода освещены в них недостаточно полно и систематически.)

На заседаниях Орфографической комиссии рассматривались также некоторые частные вопросы пунктуации: роль индивидуальных рекомендаций в области пунктуации (в частности, рассматривались «Некоторые грамматические соображения〉 Александра Солженицына), а также проблемы пунктуации при передаче церковнославянского текста средствами гражданской графики [Šmelev 2018; 2019].

\section{Литература}

Šmelev A.D., 2009, Orfografičeskie normy i orfografičeskie pravila, Russkij âzyk v škole, 9, pp. 70-75.

Šmelev A.D., 2018, Aleksandr Solženicyn i kodifikaciâ russkoj punktuacii, Russkij âzyk $v$ škole, 9, pp. 55-60.

Šmelev A.D., 2019, Peredača cerkovnoslavânskogo teksta sredstvami graždanskoj grafiki: možno li polučit' ee pri pomoŝi formal'noj procedury?, Komp'ûternaâ lingvistika i intellektual'nye tehnologii: po materialam ežegodnoj meždunarodnoj konferencii «Dialog», 18 (25), pp. 589-599. 